\title{
DROP PAINTING: UM CASO DE INTERDISCIPLINARIDADE NO ENSINO BILÍNGUE
}

\author{
Isabela Vieira Barbosa ${ }^{1}$ \\ Caique Fernando da Silva Fistarol ${ }^{2}$
}

\begin{abstract}
Resumo: Esse artigo visa discutir reflexões sobre a aprendizagem a partir de uma experiência interdisciplinar em uma Escola que possui a organização do currículo a partir do ensino bilíngue. Esta escola trabalha os planejamentos com ênfase na interdisciplinaridade e esta pesquisa pautase por meio de um estudo de caso entre os componentes curriculares de Arts e a língua inglesa. Para este estudo de caso, optou-se pela observação das ações decorrentes das atividades de uma sequência didática planejada para duas turmas de primeiro ano do Ensino Fundamental de uma Escola da Rede Particular bilíngue de Santa Catarina. A análise dos dados gerados ocorreu por meio da perspectiva histórico-cultural com pressupostos da interdisciplinaridade. Os dados apontam que a sequência didática possibilitou desenvolver práticas pedagógicas que enriqueceram 0 aprendizado e estímulo em língua inglesa e ampliaram a bagagem cultural dos estudantes. E essas práticas pedagógicas trabalhadas em uma perspectiva interdisciplinar bilíngue possibilitam o ensino integrado, não fragmentado em uma perspectiva de aprendizagem conceitual atrelado ao desenvolvimento linguístico.
\end{abstract}

Palavras-chave: Jackson Pollock; Artes; Interdisciplinaridade; Ensino bilíngue.

\section{1 introdução}

Os estilos de aprendizagem ou os diferentes meios de acesso aos conhecimentos se "diferem de pessoa para pessoa e são influenciadas por fatores de natureza diversa (ambiental, cultural, socioeconômico, físico e cognitivo) que determina a capacidade de adaptação dos indivíduos à aprendizagem" (PATRICIO; OSÓRIO, 2016, p. 116). Esses diferentes modos de aprender, são chamados de estilos de aprendizagem.

Patrício e Osório (2016) apontam que é fundamental compreender como os estilos de aprendizagem interferem nos processos de aprender a aprender, "não apenas para o professor poder mediar a construção de saberes dos seus alunos através do desenvolvimento de competências e habilidades necessárias a esse conhecimento, mas também para se alcançar a flexibilidade na aprendizagem"

\footnotetext{
${ }^{1}$ Mestre em Educação pela FURB. Possui Pós-Graduação em Educação Infantil e Desenvolvimento pela Universidade Cândido Mendes e especialização em Gestão Educacional pela UNIASSELVI. Possui graduação em Pedagogia pela Univali.

${ }^{2}$ Mestre em Educação pela FURB. Professor de Língua Inglesa na Rede Municipal de Ensino de Blumenau/SC. Atualmente, está como Coordenador do Ensino Bilíngue e de Língua Inglesa da Rede Municipal de Ensino de Blumenau/ SC.
}

Revista de Letras JUÇARA, Caxias - Maranhão, v. 03, n. 02, p. 224 - 238, dez. 2019 | 224 
(PATRICIO; OSÓRIO, 2016, p. 116). Os estilos de aprendizagem de cada indivíduo têm origem, nas diferentes respostas e comportamentos originados a partir das aprendizagens proporcionadas.

Nesse ínterim, os propósitos de aprendizagem têm sido influenciados pelos diferentes acontecimentos e fenômenos mundiais tais como a globalização, a abertura do mercado econômico e do advento das mídias, em especial, a internet, conforme destacam Patrício e Osório (2016),buscando "dar resposta aos problemas e desafios de um mundo em mudança e desenvolvimento" (PATRICIO; OSÓRIO, 2016, p. 117). Compreendemos então, que nessa perspectiva, temos sido testemunhas de diferentes abordagens, metodologias e organizações curriculares no campo da Educação que tem avançado de uma visão mais utilitarista para uma abordagem mais humanista e holística.

Nesse sentido, buscamos neste artigo discutir um caso de interdisciplinaridade no Ensino Bilíngue, que por meio dos componentes curriculares de artes e língua inglesa, demonstram um novo estilo de aprendizagem, em consonância com as múltiplas dimensões da existência humana conforme sugerido pela Unesco (2016).

O ensino de uma segunda língua dentro do percurso formativo da Educação Básica, é resultado de diversos fatores ocorrem no ensino em sala de aula, como a interação entre os estudantes, entre estudantes e professor, com apoio muitas vezes na ludicidade (SCHUTZ, 2011). Nos últimos anos, as novas mídias e os multiletramentos têm contribuído para transformar os processos de ensinar e de aprender em um movimento mais dinâmico. Para isso, a interdisciplinaridade tem sido planejada entre os diferentes componentes curriculares visando o ganho nas práticas pedagógicas, contribuindo para o desenvolvimento de habilidades e competências (BRASIL, 2017) nos estudantes.

A partir dessas premissas, houve o planejamento de uma prática pedagógica por meio de uma sequência didática (DOLZ; SCHNEUWLY, 2004) com duas turmas do primeiro ano do Ensino Fundamental de Anos Iniciais, de uma Escola da Rede Particular bilíngue de Santa Catarina. Dolz e Schneuwly (2004) ressaltam que as sequências didáticas proporcionam aos estudantes compreender de forma mais integrada os conceitos explorados e facilita a mobilização e 
desenvolvimento da aprendizagem em meio a atividades realizadas de forma a aliar os conceitos já adquiridos aos novos que serão abordados.

Cada uma das duas turmas de $1^{\circ}$ ano do Ensino Fundamental de Anos Iniciais possui aproximadamente 20 estudantes, e a sequência didática foi realizada interdisciplinarmente entre os componentes curriculares de Arts e língua inglesa. No plano de ensino do componente de Arts, são abordados diferentes pintores e técnicas de pinturas de países, e na sequência realizada foram trabalhados o pintor norte-americano Jackson Pollock e a técnica criada pelo pintor chamada de "drop painting", ou gotejamento em língua portuguesa.

Este plano de ensino ainda destaca, que o intuito é de identificar, observar, analisar e aplicar diferentes técnicas e procedimentos artísticos presentes em trabalhos de Arte por meio de uma vivência, bem como do estudo da biografia do pintor norte-americano. Por isso, este artigo de cunho qualitativo (BOGDAN; BIKLEN, 1999), buscou abordar os conceitos artísticos em língua inglesa, visando trabalhar a oralidade dos estudantes em língua adicional (SCHLATTER; GARCEZ, 2010) propostos para o componente curricular de Arts.

O estudo de caso "é uma categoria de pesquisa cujo objeto é uma unidade que se analisa aprofundadamente" (TRIVIÑOS, 1987, p. 133, grifo do autor) pois esta metodologia permite uma reflexão sobre um caso especifico, produzindo uma análise crítica que proporciona o planejamento, avaliação e proposição de novas ações. Tellis (1997) ainda destaca que os estudos de caso permitem em suas análises que incorporar diferentes perspectivas, como a coleta de dados, que no estudo de caso, não segue padrões tão rígidos como em pesquisas experimentais e por esta razão, se torna mais flexível para compreender o objeto observado (TELLIS, 1997).

Assim, o presente artigo está organizado, apresentando os conceitos de Ensino Bilíngue e de interdisciplinaridade, em seguida abordamos o tema da sequência didática, Jackson Pollock e a técnica de gotejamento, e posteriormente é descrito o relato das atividades desenvolvidas pelas turmas do estudo de caso. Finalizamos o presente artigo com as considerações finais do estudo de caso.

\section{Ensino bilíngue e interdisciplinaridade}


O ensino bilíngue pode ser definido como algo que ultrapassa os limites escolares e do aprendizado de um segundo idioma (MELLO, 2010). Nos últimos anos, o número de unidades educacionais ofertando o ensino bilíngue tem se ampliado, nesse sentido, faz-se mais do que importante definir como compreendemos ensino bilíngue.

Para este artigo, compreenderemos ensino bilíngue como uma organização curricular que proporciona o aprendizado de uma segunda língua para a atuação em diferentes letramentos e interações sociais com a família, amigos, artefatos culturais e mídias aos quais os estudantes têm acesso, bem como a atuação do meio no qual ele está inserido (MELLO, 2010).

Defendemos ainda, que o ensino bilíngue tem por objetivo planejar os processos de ensinar e de aprender em duas línguas, onde estas línguas não são apenas objeto de aprendizagem, serão o meio para o desenvolvimento do ensino e da aprendizagem (HORNBERGER, 1991; MELLO, 2010). Compreendemos que o ensino bilíngue abarca desde os aspectos e conceitos de cultura, a realidade histórico-cultural e conhecimentos prévios dos estudantes, além de interesses coletivos dos grupos sociais.

O conceito de ensino bilíngue nas Escolas ocorre a partir de diversas organizações curriculares, compondo-se em uma arquitetura varia e complexa. Ou seja, não há política linguística em nosso país que regulamente um formato definido de trabalho bilíngue nas unidades educacionais. Porém, percebe-se que a relevância do aprendizado de uma língua adicional tem feito as Escolas ressignificarem seus processos de ensinar e de aprender, assim como compreender como ocorrem esses diferentes letramentos em duas línguas.

O Ensino Bilíngue possibilita o biletramento, definido como todas as oportunidades em que a comunicação ocorra em duas línguas tanto na escrita, quanto na verbalidade (HORNBERGER, 1990). Essas práticas de biletramento, são ofertadas em diferentes artefatos culturais e mídias, como livros, músicas, jogos e outros materiais utilizados no processo de ensinar e aprender.

Essas transformações, proporcionadas pelas diferentes teorias de aprendizagem, organizações curriculares e novas aplicações de ensino, impulsionaram o surgimento das teorias dos multiletramentos (COPE; KALANTZSIS, 2000). Esses autores destacam, que a escolha do termo está 
relacionada a multiplicidade de mídias, de contextos histórico-culturais e variedades linguísticas com quem estabelecem relações. Logo, o conceito de multiletramentos, abarca conceitos mais amplos do que apenas a relação com à língua alvo, mas também as diferentes funções que estes artefatos exercem sobre os estudantes, remodelam as interações e práticas situadas por meio da linguagem, a ressignificando multimodalmente (COPE; KALANTZIS, 2000).

Dentro da perspectiva da Teoria dos Multiletramentos (COPE; KALANTZIS, 2000) o conhecimento humano é perpassado pelos contextos sociais, culturais e materiais, e o conhecimento construído é parte do processo de interações colaborativas com outros saberes, diferentes habilidades, áreas de conhecimento, contextos e perspectivas. Cope e Kalantzis (2000), dividiram essa discussão sobre uma pedagogia complexa e ampla, em quatro fatores: a prática situada, instrução explicita, enquadramento crítico e prática transformadora.

De acordo com essas teorias houve o planejamento para este estudo de caso em que se buscou unir interdisciplinarmente conceitos de Arts com a língua inglesa, em uma sequência didática sob o tema do pintor norte-americano Jackson Pollock. Japiassu (1976) destaca que interdisciplinaridade, proporciona diferentes trocas de conceitos, experiências e vivências dentro de um projeto, pela unificação e associação dos diferentes componentes curriculares. Esses projetos permitem ao estudante 0 estabelecimento de relações entre as diferentes áreas do conhecimento e possam contextualizar o tema que é mediado pelo professor.

É possível reconhecer "um empreendimento interdisciplinar todas as vezes em que ele conseguir incorporar os resultados de várias especialidades, que tomar de empréstimo a outras disciplinas certos instrumentos e técnicas metodológicos" (JAPIASSU, 1976, p 75). Assim, compreendemos que as diferentes definições acerca da interdisciplinaridade, apontam para práticas que visam ampliar os conhecimentos dos estudantes, mas se dispõem a fazer uma revisão do como fazer, para que fazer e por que fazer, levando os estudantes ampliar não apenas os conhecimentos científicos propostos pela atividade, mas pela reflexão da experiência vivenciada.

\section{Jackson Pollock e a técnica de gotejamento}


Para falarmos da experiência vivenciada por meio desta sequência didática, precisamos entender quem é o pintor abordado no componente curricular de Arts. Dentro da proposta do Ensino Bilíngue da instituição observada, o componente curricular busca compreender o fenômeno visual, seus diferentes processos e produtos artísticos e culturais, nos diferentes países que são estudados nos diferentes anos.

No primeiro ano do Ensino Fundamental de Anos Iniciais, essa escolha ocorre a partir dos principais nomes da arte dos países onde a língua inglesa é considerada língua oficial, entre eles, os Estados Unidos. Nesse sentido, no próprio plano de ensino de Arts, o pintor norte-americano Jackson Pollock consta como conteúdo a ser abordado pelos professores.

Jackson Pollock, é considerado por muitos especialistas na área, um dos principais artistas norte-americanos, como Silva (2001) resgata uma publicação do ano de 1949 da renomada revista norte-americana Life, que aponta Pollock como "um dos maiores artistas vivos dos Estados Unidos".

O título de um artigo, publicado em 1949 pela revista Life - "Jackson Pollock, is he the greatest living painter in the United States?" - dá conta do impacto de sua obra. Landau viu nela "a fusão moderna da audácia de Prometeu com a energia e a força sobre-humanas de Hércules" (SILVA, 2001, p. 22).

A escolha por Jackson Pollock, pode ser justificada pelo pintor ser um dos principais representantes do Expressionismo Abstrato nos Estados Unidos, conhecido mundialmente pela técnica de "drop painting" traduzida para a língua portuguesa como técnica de gotejamento (SILVA, 2001) durante os anos de 1946 e 1947, levando sua carreira ao auge. Ainda se destaca que poucos artistas se aprofundaram tanto em uma própria técnica e abordou tão artisticamente o inconsciente do ser humano como este artista (SILVA, 2010). Infelizmente, no ano de 1956 o pintor faleceu em um trágico acidente de automóvel.

O estilo de pintura que consolidou a carreira de Jackson Pollock, se destacou por dispensar os materiais tradicionais de pintura à época, como superfícies planas, pincéis e cavaletes. "Pollock parte realmente do zero, do pingo de tinta, do pingo de tinta que deixa cair na tela" (ARGAN, 2002, p. 531-532) 
rompendo com a tradição e utilizando dos movimentos do corpo para conduzir a pintura, como veremos mais a seguir.

\section{Drop painting}

Com o intuito de relacionar o conteúdo do componente curricular de Arts que abordasse o pintor norte-americano Jackson Pollock e a língua inglesa, foi elaborada uma sequência didática interdisciplinar com foco nas atividades de compreensão auditiva, oralidade e pintura.

A proposta da atividade realizada, tinha como foco o protagonismo dos estudantes na elaboração de uma obra baseada no pintor Jackson Pollock, mas que ao mesmo tempo, conhecessem a técnica inventada pelo pintor e pudessem vivenciar toda essa experiência.

Então, os estudantes foram apresentados ao pintor Jackson Pollock, por meio de slides, que apresentavam o artista, com foto, datas de nascimento e falecimento, para que os estudantes tivessem a oportunidade de iniciar a atividade conhecendo quem era a pessoa a ser estudada.

Durante esse momento, os estudantes tentaram elaborar questões sobre o pintor em inglês, e quando não conseguiam utilizar apenas a língua inglesa, faziam a alternância de línguas, conhecido como code-switching ${ }^{3}$ (GROSJEAN, 1982), visando utilizar as estruturas e vocabulários já desenvolvidos em língua inglesa.

Em seguida, os estudantes foram apresentados à um vídeo do pintor Jackson Pollock realizando uma pintura. O vídeo era composto de imagens antigas, apresentando o pintor norte-americano, no jardim de sua casa com uma grande tela ao chão. É possível observar como o pintor maneja os pinceis e goteja sobre a tela as tintas de diferentes cores, "respingando" a tinta com traçados fortes e sem encostar sobre a tela no vídeo.

Como apresentamos anteriormente, entre os objetivos do plano de ensino da instituição para o componente curricular de Arts, destacamos que o documento frisa que busca compreender os fenômenos visuais, bem como os diferentes

\footnotetext{
${ }^{3}$ Grosjean (1982) define code-switching como o uso de mais de uma língua durante a execução da fala. O autor aponta que essa troca pode envolver uma palavra, frase ou sentença. Diferentemente de pegar emprestada uma palavra de outra língua, no code-switching a palavra não se integra fonologicamente ou morfologicamente à língua dominante, em vez disso, ocorre uma mudança total para a outra língua.
}

Revista de Letras JUÇARA, Caxias - Maranhão, v. 03, n. 02, p. 224 - 238, dez. 2019 | 230 
processos artísticos e culturais, nos diferentes países trabalhados, neste caso, os Estados Unidos. Assim, a apresentação da técnica de gotejamento possibilita expandir a bagagem cultural dos estudantes através de uma técnica de pintura, e concomitantemente aprofundar os conhecimentos acerca do movimento Expressionista Abstrato, representado por Jackson Pollock aos estudantes.

Após o início da sequência didática, na qual os estudantes puderam assistir ao vídeo, foi exposto aos estudantes que a atividade a ser realizada, seria uma releitura, ou seja, uma obra inspirada na obra de Pollock.

Diante do exposto, diversos estudantes questionam, que a obra por ser abstrata, conceito já estudado previamente, não poderia ser totalmente copiado, pois o gotejamento não seguia uma lógica de pintura. Nesse instante então, a professora argumentou que para realizar uma releitura do pintor Jackson Pollock, a técnica de pintura precisaria ser a mesma, ou seja, o gotejamento, e não seria necessário realizar uma cópia das obras já realizadas pelo pintor. Novamente, fora reforçado que os movimentos corporais livres do Jackson Pollock seriam os condutores dessa releitura, mesmo que, o produto final não pudesse ser imitado.

A próxima etapa então da sequência didática, fora levar os estudantes para um ambiente externo a sala de aula, onde os estudantes foram apresentados aos materiais que seriam utilizados.

Figura 1: Materiais utilizados

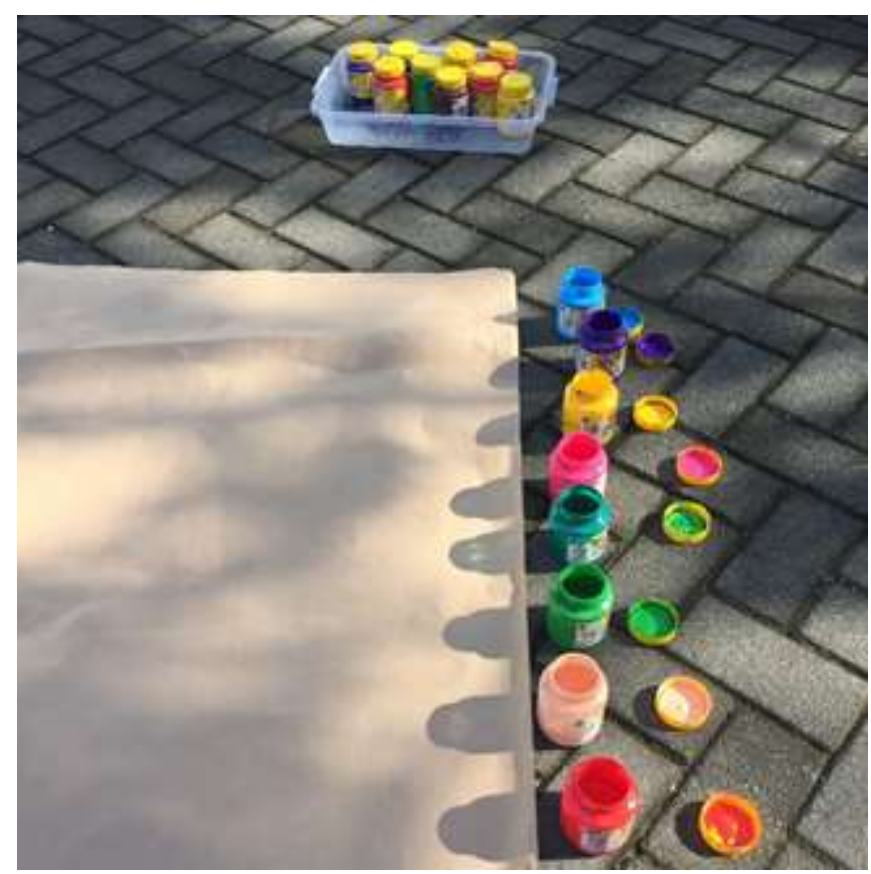

Revista de Letras JUÇARA, Caxias - Maranhão, v. 03, n. 02, p. 224 - 238, dez. 2019 | 231 
Fonte: acervo pessoal

Assim como os estudantes observaram previamente no vídeo sobre o pintor norte-americano, depararam-se com os materiais dispostos como na figura 1. Encontraram uma folha de papel pardo e diferentes tons de tinta.

Esse primeiro momento, chamado de Prática situada por Cope e Kalantzis (2005), é o momento da atividade onde a sequência didática fora apresentada ao aluno, e a partir do já conhecido, o objetivo da atividade é contextualizado.

Os estudantes foram orientados a escolher a cor do seu interesse, molhar o pincel na cor e gotejar sobre a folha com movimentos a sua escolha. Os alunos poderiam trocar de cor, poderiam respingar sobre a região da folha escolhida, porém assim como a técnica do pintor, não poderiam encostar o pincel sobre 0 papel pardo.

Esse momento de vivenciação da atividade, é chamado por Instrução Explícita (COPE; KALANTZIS, 2005) por se referir ao momento em que os estudantes se envolvem na atividade alvo, podendo colocar em prática os conhecimentos prévios, as orientações até então apenas expostos pelo professor.

Conforme a atividade foi sendo realizada percebe-se que essa vivência está pautada na teoria histórico-cultural, pois o componente de Arts atrelado a língua inglesa desenvolve-se a partir da ludicidade nos Anos Iniciais e se concentra no desenvolvimento dos aspectos éticos, estéticos e políticos, uma vez que esta desperta a criticidade, reflexão e a construção da autonomia. Logo,

O processo de ensino-aprendizado na escola deve ser construído, então, tomando como ponto de partida o nível de desenvolvimento real da criança - num dado momento e com relação a um determinado conteúdo a ser desenvolvido - e como ponto de chegada os objetivos estabelecidos pela escola, supostamente adequados à faixa etária e ao nível de conhecimento e habilidades de cada grupo de crianças. (VIGOTSKI, 1997, p. 62) 
Figura 2: Técnica "drop painting"

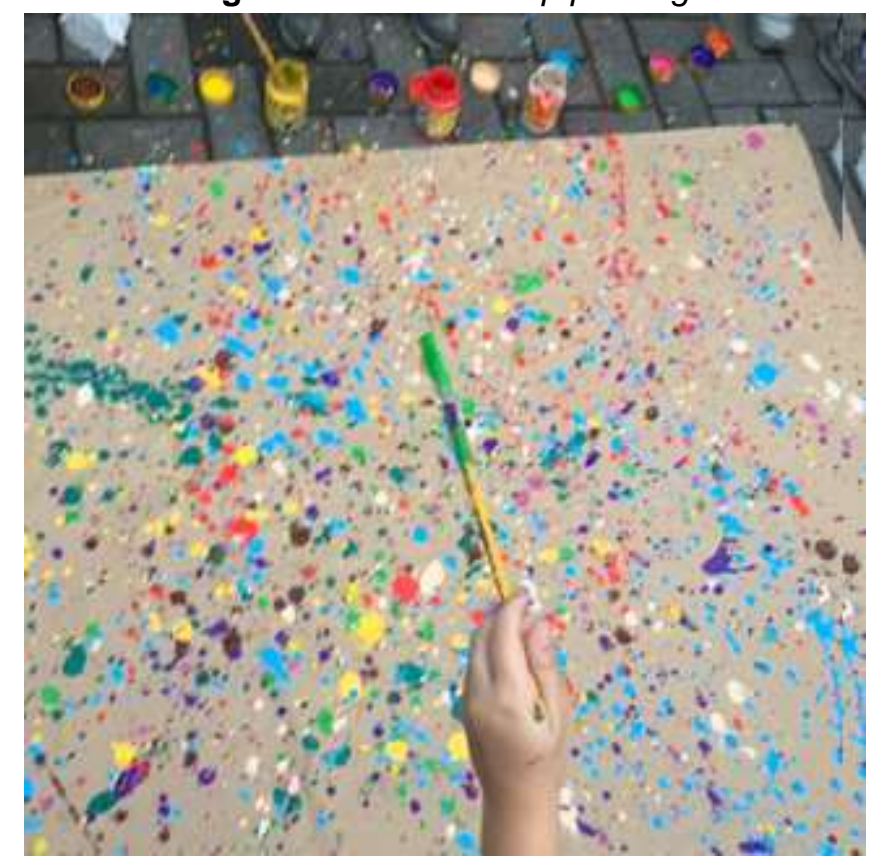

Fonte: acervo pessoal

Ou seja, durante a própria sequência didática, os estudantes ainda tiveram momentos que proporcionaram a eles analisar não apenas o que haviam aprendido antes de iniciar a pintura com a técnica de gotejamento, mas as dificuldades, os jeitos, os "erros" ou "acertos" (conforme seus discursos ao longo da atividade com a técnica) no seu engajamento da pintura, e quais cores, locais deveriam ser pintados, por exemplo. Esse momento em que os estudantes analisam a execução da tarefa, constroem criticamente suas afirmações, seus pontos de vista e debatem sobre as causas e efeitos da atividade, é chamado de Enquadramento Crítico (COPE; KALANTZSIS, 2005).

Esse momento de análise por parte dos estudantes, possibilita também um enfoque crítico não apenas ao seu trabalho realizado, mas para o discurso sobre questões artísticas. Esse discurso revela o conhecimento, as crenças, as ideologias, bem como o desenvolvimento dos planos ético, estético e políticos, conforme a Base Nacional Comum Curricular (BRASIL, 2017) e demais documentos norteadores da Educação. No plano de ensino da instituição, consta como habilidades a serem desenvolvidas no componente de Arts, a habilidade de identificar diferentes técnicas artísticas, e ao longo da utilização da técnica de gotejamento, os estudantes puderam observar os diferentes movimentos que são 
necessários para a execução, e criticamente ainda se posicionaram sobre as diferenças com outras pinturas e até a utilização de outros materiais.

Para isso, fora necessário por parte dos estudantes ainda, observar e analisar, não apenas a execução e os procedimentos artríticos, mas relacioná-los a outros já observados dentro e fora do ambiente escolar, e a bagagens artísticas prévias.

Figura 3: Estudantes realizando a pintura

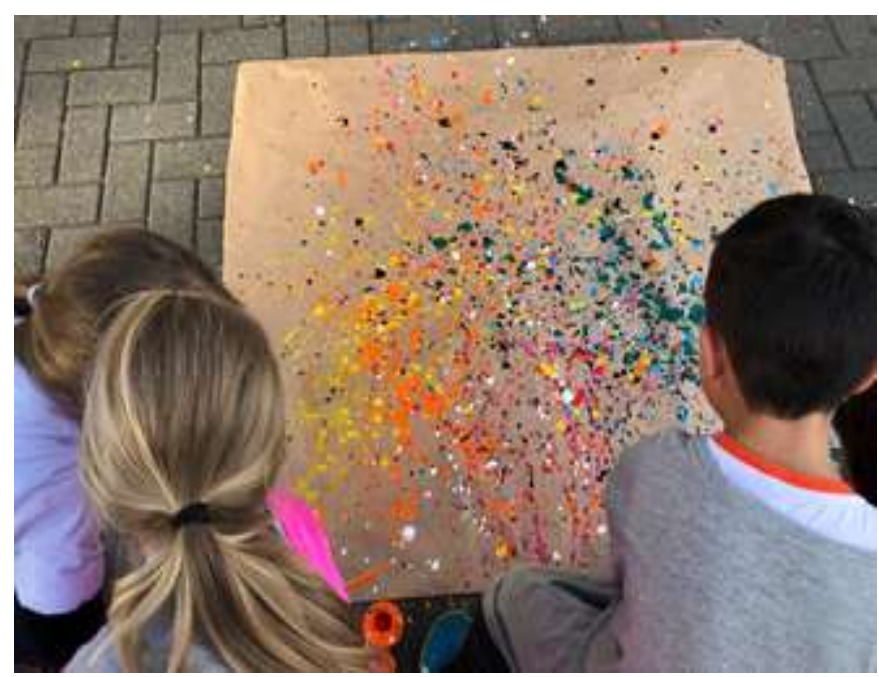

Fonte: acervo pessoal

Vigotski (2000) em seus estudos sobre a constituição da mente, contemplou as dimensões biológicas e sociais dos indivíduos, estruturando sua teoria em quatro eixos principais: atividade mediada; interação social; conduta intencional e voluntária; influência das condições socioculturais.

Os quatro eixos principais da teoria vigotskiana (2000) se relacionam, entretanto, podemos destacar um ponto central, que são as interações pessoais. Nesse sentido, a teoria histórico-cultural de Vigotski (2000) aponta que o sujeito não está isolado no processo de aprendizagem, mas que o seu envolvimento e interação com outros indivíduos é que poderão possibilitar a sua aprendizagem. A aprendizagem não ocorrerá apenas em virtude da mediação do professor, a aprendizagem "pode ser constituída por objetos culturais, situações sociais e, principalmente, pela linguagem, que, por estar carregada de significados, torna-se o signo fundamental para a internalização das coisas da cultura" (SILVA; ALMEIDA; FERREIRA, 2011, p. 221) 
Assim, ressaltamos que na etapa, chamada de Prática Transformada (COPE; KALANTZIS, 2005) o professor conjuntamente com os diferentes objetos culturais e as situações proporcionadas pela sequência didática, atuam como mediadores para ajudar no processo de consolidação dos conhecimentos dos estudantes.

Nessa sequência didática, esse momento ocorreu ao fim da atividade, em um debate, onde os estudantes colocaram seus posicionamentos, fizeram suas críticas, deram suas opiniões e demonstraram seu próprio encantamento com a construção coletiva da obra.

Podemos observar então, que o processo de apropriação de conhecimento e cultural dos estudantes percorreram diferentes etapas: inicialmente influenciadas pelos fatores sociais, que promovem uma interação do aprendiz com o meio onde ela está inserida, para em seguida, o sujeito atuar sobre o meio e si mesmo. Essa primeira etapa foi observada, através das influências exercidas pela orientação da professora e do vídeo que apresentou o pintor e técnica da obra a ser (re)produzida. E o segundo momento, onde o estudante atua sobre o meio, foi possível de ser percebido através da criação por parte da turma de uma obra de arte usando a técnica drop painting criada por Jackson Pollock.

Figura 4: Obra finalizada

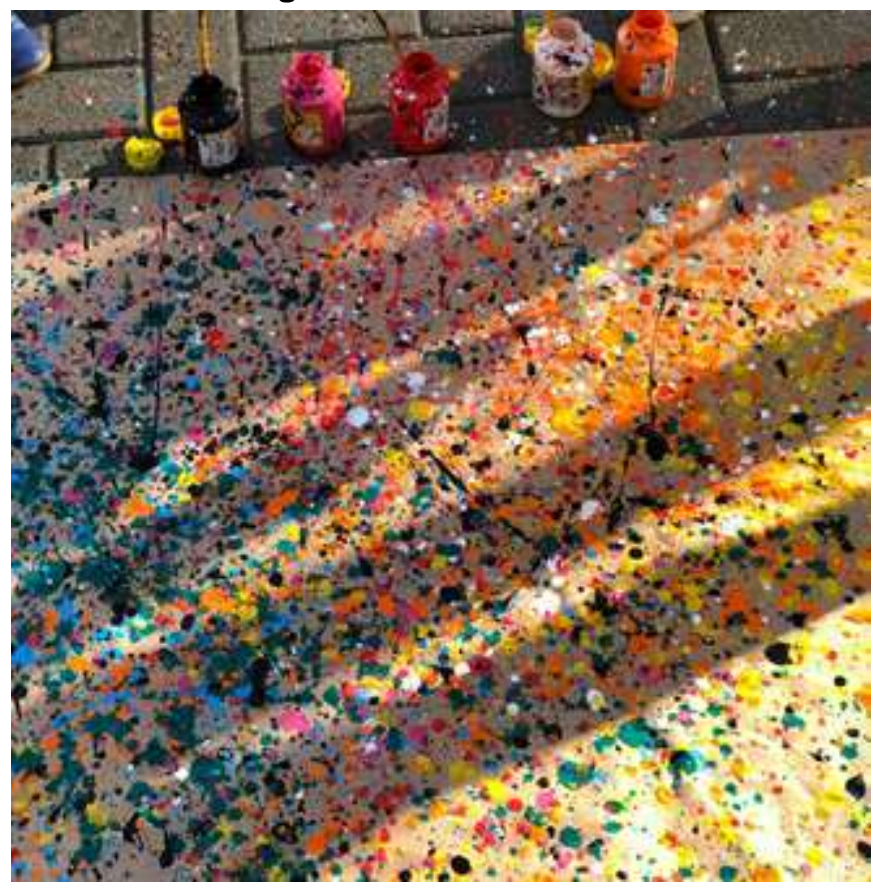

Fonte: acervo pessoal

Revista de Letras JUÇARA, Caxias - Maranhão, v. 03, n. 02, p. 224 - 238, dez. 2019 | 235 
Toda a sequência didática realizada, visou proporcionar aos estudantes, momentos nos quais eles pudessem explorar a pintura expressionista e a técnica de gotejamento, mas nas quais eles fossem protagonistas e o professor atuasse apenas como mediador. Libanêo (2004, p.5) destaca que a função do professormediador, é possibilitar o "desenvolvimento das capacidades cognitivas e operativas" dos seus estudantes, uma vez que a ele, professor, cabe proporcionar meios necessários e vivências para que os estudantes possam se apropriar dos diferentes campos do saber.

\section{Considerações finais}

O presente artigo teve como objetivo discutir reflexões sobre a aprendizagem a partir de uma experiência interdisciplinar em uma Escola que possui a organização do currículo a partir do ensino bilíngue.

A sequência didática realizada e a observação das duas turmas em meio as aulas de língua inglesa, permitiu perceber que o ensino bilíngue a partir de uma perspectiva histórico-cultural em que interdisciplinarizou o ensino de língua inglesa ao componente curricular de Arts auxiliou na aprendizagem contextualizada de conceitos importantes para o desenvolvimento de habilidades e competências, tanto linguísticas, quanto artísticas favorecendo o agenciamento, a autonomia, além do olhar ético, estético e político para a vivência proporcionada a estes estudantes.

São práticas pedagógicas como esta analisada neste artigo, que enriqueceram o aprendizado e estímulo em língua inglesa e ampliaram a bagagem cultural dos estudantes em uma perspectiva de ensino não fragmentado. Essa não fragmentação ocorre quando os diferentes saberes linguísticos, científico, tecnológico, lógico-matemático, entre outros forem trabalhados interdisciplinarmente favorecendo habilidades e competências de modo a se somar aos diferentes conceitos e desenvolvendo o pensamento crítico e criativo e resolução de demandas ocasionando a transformação social em comunidade.

Nessa perspectiva, pudemos observar um maior êxito na apropriação do conhecimento pelos estudantes em virtude da interdisciplinaridade. Edgar Morin (2000) expressa em seus estudos a necessidade de desenvolver nos alunos 
competências que vão além dos conhecimentos específicos, mas que englobem o que o autor chama de uma "inteligência geral" que possibilite ao aluno discernir os diferentes contextos e a interação dos elementos.

\title{
DROP PAINTING: A CASE OF INTERDISCIPLINARITY IN BILINGUAL TEACHING
}

\begin{abstract}
This article aims to discuss reflections on learning from an interdisciplinary experience in a school that has the organization of curriculum from bilingual education. This school works planning with an emphasis on interdisciplinarity and this research is based on a case study between the curricular components of Arts and the English language. For this case study, we chose to observe the actions resulting from the activities of a didactic sequence planned for two first-year classes of elementary school of a bilingual private school in Santa Catarina. The analysis of the generated data occurred through the historical-cultural perspective with assumptions of interdisciplinarity. The data indicate that the didactic sequence made it possible to develop pedagogical practices that enriched the learning and stimulation in English language and broadened the students' cultural background. And these pedagogical practices worked from a bilingual interdisciplinary perspective enable integrated, non-fragmented teaching from a conceptual learning perspective linked to linguistic development.
\end{abstract}

Keywords: Jackson Pollock; Arts; Interdisciplinarity; Bilingual education.

\section{Referências}

ARGAN, G. C. Arte Moderna. Tradução: Denise Bottmann e Frederico Carotti. São Paulo: Companhia das Letras, 2002.

BOGDAN, R.; BIKLEN, S. Investigação qualitativa em educação: uma introdução à teoria e aos métodos. Porto: Porto Editora, 1999.

DOLZ, J.; SCHNEUWLY, B. O oral como texto: como construir um objeto de ensino. In: SCHNEUWLY, B.; DOLZ, J. Gêneros orais e escritos na escola. Tradução de Roxane Rojo e Glaís Sales Cordeiro. Campinas, SP: Mercado das Letras, 2004.

GROSJEAN, F. Life with two languages: an introduction to bilingualism. Cambridge, Mass.: Harvard University Press, 1982.

HORNBERGER, N. H. 2004. The Continua of Biliteracy and the Bilingual Educator: Educational Linguistics in Practice. International Journal of Bilingual Education and Bilingualism. Pennsylvania, USA. Volume 7. Issues 2\&3, pp.155171.

JAPIASSU, Hilton. Interdisciplinaridade e patologia do saber. Rio de Janeiro: Imago, 1976.

KALANTZIS, M; COPE, B. Learning by Design Project Group. Learning by Design, Victorian Schools Innovation Commission \& Common Ground, Melbourne, 2005.

Revista de Letras JUÇARA, Caxias - Maranhão, v. 03, n. 02, p. 224 - 238, dez. 2019 | 237 
LIBÂNEO, J. C. A didática e aprendizagem do pensar e do aprender: a Teoria Histórico-cultural da Atividade e a contribuição de Vasili Davydov. Revista Brasileira e Educação. Rio de Janeiro, n. 27, Set/Out/Nov/Dez 2004. Disponível em: http://www.scielo.br/pdf/rbedu/n27 /n27a01.pdf. Acesso em 10/11/2018.

MORIN, E. Para sair do século XX. Rio de Janeiro, Nova Fronteira, 1986.

PATRÍCIO, M. R.; OSÓRIO, A. Novos Estilos de Aprendizagem em Contexto de Aprendizagem Flexível e ao Longo da Vida Aberta. In: CONGRESSO MUNDIAL DE ESTILOS DE APRENDIZAGEM, 7., 2016, Bragança. Anais.... Bragança: Instituto Politécnico de Bragança, 2016. v. 1, p. 110 - 121.

SCHUTZS, R. A idade e o aprendizado de Línguas. Made in Brazil <http://www.sk.com.br/sk-mapre2.html>. Online. 24 de fevereiro de 2008. Acesso em 22/09/2018.

SILVA, S. G. Jackson Pollock e a descoberta do inconsciente na arte americana do pós-guerra. ARS (São Paulo) [online]. 2014, vol.12, n.24, pp.20-41. ISSN 16785320 .

SILVA, S. M. C; ALMEIDA, C. M. C; FERREIRA, S. Apropriação cultural e mediação pedagógica: contribuições de Vigotski na discussão do tema. Psicol. estud. [online]. 2011, vol.16, n.2, pp.219-228. ISSN 1413-7372.

UNESCO. Repensar a educação: rumo a um bem comum mundial?. Brasília: UNESCO Brasil, 2016.

VIGOTSKI, L. S. Obras Escogidas III. Madri: Editora Visor Dis, 2000.

Data da Submissão: 02/11/2019

Data da Aprovação: 09/12/2019 